\title{
OS PROCESSOS SELETIVOS SIMPLIFICADOS DA UEMG: ANÁLISE DA PRECARIZAÇÃO dO TRABALHO DOCENTE DOS PROFESSORES DESIGNADOS
}

\begin{tabular}{c}
\hline UEMG'S SIMPLIFIED SELECTION PROCESSES: \\
ANALYSIS OF THE PRECARIZATION OF THE \\
TEACHING WORK OF UNTENURED PROFESSORS \\
\hline LOS PROCESOS SELECTIVOS SIMPLIFICADOS DE LA UEMG: \\
ANÁLISIS DE LA PRECARIZACIÓN DEL TRABAJO \\
DOCENTE DE LOS PROFESORES DESIGNADOS \\
\hline
\end{tabular}

\section{Adelino Francklin ${ }^{1}$ Maria Cristina da Silveira Galan Fernandes ${ }^{2}$}

\begin{abstract}
RESUMO: O artigo analisa as implicações do Processo Seletivo Simplificado (PSS) da Universidade do Estado de Minas Gerais (UEMG) para o trabalho docente dos professores designados. Esse estudo justifica-se pelo elevado percentual de professores designados da UEMG em relação ao número de professores efetivos e pelos prejuízos para o tripé ensino, pesquisa e extensão na universidade. O estudo é qualitativo e utilizou-se de pesquisa bibliográfica e documental. Por meio da bibliografia consultada, dos conceitos de "campo" e habitus, de Pierre Bourdieu e da análise de um dos editais de PSS da UEMG, constataram-se elementos de precarização do trabalho docente dos professores designados desta universidade.
\end{abstract}

PALAVRAS-CHAVE: Precarização. Professores Temporários. Universidade do Estado de Minas Gerais.

ABSTRACT: The article analyzes the implications of the Simplified Process (PSS) of Minas Gerais State University (UEMG) for the teaching work of untenured professors. This study is justified by the high percentage of UEMG's untenured professors in relation to the number of tenured professors and by the damages to the teaching-research extension triad in the university. The research is qualitative and used the bibliographic and documentary methods. By means of the consulted bibliography, concepts of the "field" and habitus, by Pierre Bourdieu and the analysis of one of the UEMG's PSS announcements, precarization elements were verified in the teaching work of untenured professors of the university.

KEYWORDS: Precarization. Temporary Professors. Universidade do Estado de Minas Gerais.

RESUMEN: El artículo analiza las implicaciones del Proceso Selectivo Simplificado (PSS) de la Universidad del Estado de Minas Gerais (UEMG) para el trabajo docente de los profesores designados. Este estudio se justifica por el elevado porcentaje de profesores designados de la UEMG en relación con el número de profesores efectivos y por los perjuicios para el trípode enseñanza, investigación y extensión en la universidad. La investigación es cualitativa y se utilizó del método bibliográfico y documental. Por medio de la bibliografía consultada, de los conceptos de "campo" y habitus, de Pierre Bourdieu y del análisis de uno de los llamados públicos del PSS de la UEMG, se constató elementos de precarización del trabajo docente de los profesores designados de esta universidad.

PALABRAS CLAVE: Precarización. Profesores temporales. Universidade do Estado de Minas Gerais.

\footnotetext{
${ }^{1}$ Submetido em: 10/06/2018 - Aceito em: 29/07/2018 - Publicado em: 18/01/2019
}

\begin{tabular}{l|c|c|c|c|c|c|} 
(C) Rev. Educ. Perspec. & Viçosa, $M G$ & v.9 & n.3 & p.694-713 & set./dez. 2018 & eISSN 2178-8359 \\
\hline
\end{tabular}




\section{INTRODUÇÃO}

No ano de 2015, a Universidade do Estado de Minas Gerais (UEMG) possuía 92\% de seu quadro de docentes na condição de designados ${ }^{i}$. No segundo semestre de 2017, este número foi reduzido para aproximadamente $62 \%$ de professores com contratação temporária, em função da nomeação dos aprovados no concurso público iniciado no ano de 2014. No entanto, o número de professores com cargos efetivos ainda é pequeno perante o número de designados (JORNAL DA UEMG, 2016).

Os professores designados são contratados pela UEMG mediante editais de Processo Seletivo Simplificado (PSS), ofertando vagas a serem ocupadas pelo período de um ano, aceitando-se a prorrogação pelo mesmo período.

À luz dos conceitos de "campo" e habitus, em Pierre Bourdieu, apresentamos um recorte de pesquisa de doutorado, visando analisar a precarização do trabalho docente em face da realização dos processos seletivos simplificados da UEMG.

Bourdieu (1983, p. 122) afirma que "o universo da mais "pura' ciência é um "campo" social como outro qualquer, com suas relações de força e monopólios, suas lutas e estratégias, seus interesses e lucros, mas onde todas essas invariantes revestem formas específicas". Consideramos a universidade ou o "campo" científico, como um tipo de "campo" social, visto que as lutas neste "campo" se revestem de maneira semelhante à do "campo" social.

Por habitus, Bourdieu (1983, p. 162) explica que:

[...] é, com efeito, princípio gerador de práticas objetivamente classificáveis e, ao mesmo tempo, sistema de classificação (principium divisionis) de tais práticas. Na relação entre as duas capacidades que definem o habitus, ou seja, capacidade de produzir práticas e obras classificáveis, além da capacidade de diferenciar e de apreciar essas práticas e esses produtos (gostos), é que se constitui o mundo social representado, ou seja, o espaço dos estilos de vida.

Neste sentido, entendemos que o habitus do professor universitário passa por alterações diante das disputas que possam ocorrer no "campo" científico. "O "campo”, como parte dos contextos contínuos em que vivemos, estrutura o habitus, enquanto ao mesmo tempo o habitus é a base da compreensão que os atores têm de suas vidas, incluindo o "campo"”, (GRENFELL, 2018, p. 77). Assim, entendemos que o tripé da universidade (ensino, pesquisa e extensão) tem sido prejudicado diante da interrupção de contratos e instabilidade no cargo dos professores designados. Por essa razão, a pesquisa se justifica, tendo em vista a necessidade de análise dos impactos da instabilidade dos cargos dos professores designados para a continuidade de projetos dentro da universidade e as alterações no habitus professoral desses docentes diante das disputas encontradas no "campo".

\begin{tabular}{l|c|c|c|c|c|c} 
() Rev. Educ. Perspec. & Viçosa, $M G$ & v.9 & n.3 & p.694-713 & set./dez. 2018 & eISSN 2178-8359 \\
\hline
\end{tabular}


O número elevado de professores designados na UEMG torna relevante o estudo sobre o processo de precarização do trabalho desses professores. Além do número alarmante de professores designados nesta Universidade, as dificuldades financeiras enfrentadas pelos estados brasileiros, a exemplo do estado de Minas Gerais, em que o governo estadual decretou calamidade financeira no dia 05 de dezembro de 2016, dão a ver um cenário com número elevado de contratação de professores temporários para os próximos anos. A suspensão de concursos públicos para provimento de cargos efetivos é uma das medidas propostas diante do argumento da contenção dos gastos públicos.

Adotamos para esta pesquisa uma abordagem qualitativa (TRIVIÑOS, 1987). Ao buscarmos os elementos de precarização do trabalho docente do professor designado da UEMG, direcionamos nosso olhar para os seres humanos envolvidos. Desse modo, procuramos ir além de uma quantificação em nossas análises.

Para o recorte apresentado neste artigo, realizamos uma pesquisa bibliográfica e documental (GIL, 2008) no primeiro semestre de 2018 mediante consulta de livros, artigos científicos, dissertações de mestrado e teses de doutorado no que tange às categorias de professores temporários; Instituições de Ensino Superior (IES) públicas estaduais; precarização e Universidade do Estado de Minas Gerais. As buscas pelos trabalhos acadêmicos foram realizadas pelo site de periódicos da Scielo, banco de teses da Coordenação de Aperfeiçoamento de Pessoal de Nível Superior (CAPES), pelos Grupos de Trabalhos (GTs) da Associação Nacional de Pós-Graduação e Pesquisa em Educação (ANPEd), pelo site da Rede Universitas/Br, pelo Google Acadêmico e, ainda, pela biblioteca da Universidade Federal de São Carlos (UFSCar).

No levantamento documental foram consultados os Jornais impressos e online da UEMG e um dos editais de PSS disponibilizados no site da instituição (UEMG, 2018). Selecionamos estudos e documentos a partir dos anos 2000, levando-se em consideração as reformas de Estado e da Educação implementadas pelo governo mineiro a partir de 2003 (SANTOS; VIEIRA, 2015).

Neste artigo analisamos os resultados obtidos em que se evidenciam as condições de trabalhos dos professores designados da UEMG, bem como as implicações do PSS da universidade para o trabalho docente, apontando que no atual cenário político, marcado pela adoção de políticas e programas neoliberais, o PSS tende a se perpetuar, substituindo o concurso público de provas e títulos, como previsto pela Constituição Federal. 


\title{
AS CONDIÇÕES DE TRABALHO DOS PROFESSORES DESIGNADOS DA UEMG
}

No atual contexto histórico ocorre a denominada mundialização do capital (CHESNAIS, 1996). A formação de oligopólios mundiais e a mundialização da concorrência são algumas das manifestações deste fenômeno analisado pelo autor, que assume a preferência pelo termo mundialização em detrimento do nome globalização.

\begin{abstract}
A mundialização é o resultado de dois movimentos conjuntos, estreitamente interligados, mas distintos. O primeiro pode ser caracterizado como a mais longa fase de acumulação ininterrupta do capital que o capitalismo conheceu desde 1914 . $\mathrm{O}$ segundo diz respeito às políticas de liberalização, de privatização, de desregulamentação e de desmantelamento de conquistas sociais e democráticas, que foram aplicadas desde o início da década de 1980, sob o impulso dos governos Thatcher e Reagan (CHESNAIS, 1996, p. 34).
\end{abstract}

O neoliberalismo inglês, implementado por Margaret Thatcher gerou diversas consequências negativas para a classe trabalhadora inglesa na década de 1980. Antunes (2009) explica que houve grande flexibilização do mercado de trabalho, o que implicou na precarização do trabalho, principalmente quanto aos direitos sociais.

O segundo movimento que resultou na mundialização do capital estudado por Chesnais (1996) foi adotado de modo mais incisivo no Brasil a partir do governo de Fernando Collor de Mello (1990-1992), com a abertura da economia nacional para o capital estrangeiro e a adoção de medidas neoliberais, que renderam consequências para diversos setores da sociedade.

A precarização do trabalho, em face das flexibilizações dos contratos trabalhistas, passou a trazer efeitos nefastos. Sobre as medidas de cunho neoliberal, Harvey (2014, p. 180-181) afirma:

Os indivíduos entram no mercado de trabalho como pessoas dotadas de um caráter, como indivíduos inseridos em redes de relações sociais e socializados de diferentes maneiras, como seres físicos identificáveis por meio de certas características (como fenótipo e gênero), como indivíduos que acumularam várias capacidades (por vezes designadas como 'capital humano') e gostos (por vezes designados como 'capital cultural') e como seres humanos que têm sonhos, desejos, ambições, esperanças, dúvidas e temores. Mas, para os capitalistas, esses indivíduos são um mero fator de produção, ainda que não um fator indiferenciado, já que os empregadores exigem uma mão de obra com certas qualidades, como força física, capacidades especializadas, flexibilidade, docilidade etc., apropriadas para a realização de certas tarefas. Os trabalhadores são empregados por meio de contratos, e no esquema neoliberal de coisas preferem-se contratos de curto prazo a fim de maximizar a flexibilidade. 
A adoção de contratos trabalhistas curtos e/ou flexíveis tem ocorrido com frequência nas IES. Dentro desta perspectiva, Santos (2014), ao abordar a influência neoliberal nas IES comenta que no contexto atual, a universidade apresenta formas de trabalho precárias para os docentes, tanto no setor público quanto no privado. No caso das universidades públicas, verifica-se a implementação de políticas neoliberais, a redução salarial e a queda da qualidade do ensino superior como consequência das medidas recomendadas, por exemplo, pelo Banco Mundial, entre outros organismos multilaterais.

A flexibilização do trabalho docente, no entendimento do Ministério da Educação (MEC), assume o significado de eliminação do concurso público e a dedicação exclusiva, substituindo-os por contratos temporários e precários (CHAUÍ, 1999).

Entre as IES públicas, as universidades estaduais têm vivenciado um processo de precarização do trabalho docente, especialmente no tocante ao trabalho dos professores temporários. Constata-se que esses professores, além de não possuírem estabilidade no emprego, lecionam disciplinas que não possuem aderência com a sua formação acadêmica, recebem uma remuneração menor que a dos professores efetivos, trabalham em mais de uma instituição de ensino para complementar a renda mensal e, dificilmente orientam projetos de pesquisa, extensão e trabalhos de conclusão de curso (MANCEBO, 2007a; AMADO; MANCEBO, 2003; MANCEBO; GOULART; DIAS, 2010; PIMENTA; ANASTASIOU, 2014; PASSOS, 2014).

De acordo com Tavares (2011, p. 94) os "docentes temporários estão muito mais susceptíveis a uma série de exposições à intensificação e à exploração daquilo que se realiza em termos de produção do conhecimento acadêmico". O habitus dos professores temporários, destarte, pode sofrer alterações. Wacquant (2017, p. 214) explica que:

\begin{abstract}
O habitus é uma noção mediadora que ajuda a romper com a dualidade de senso comum entre indivíduo e sociedade ao captar 'a interiorização da exterioridade e a exteriorização da interioridade', ou seja, o modo como a sociedade se torna depositada nas pessoas sob a forma de disposições duráveis, ou capacidades treinadas e propensões estruturadas para pensar, sentir e agir de modos determinados, que então as guiam nas suas respostas criativas aos constrangimentos e solicitações do seu meio social existente.
\end{abstract}

Assim como para Pierre Bourdieu "cada "campo" é definido por leis próprias que determinam a entrada, a permanência ou a saída dos atores sociais que incorporam, desde cedo, as estruturas objetivas relativas ao meio em que vivem" (BALDINO; DONENCIO, 2014 , p. 265-266), pressupõe-se que as condições precárias de trabalho dos professores temporários nas IES públicas possam influenciar o habitus professoral desses profissionais. Os autores consideram que o habitus professoral é um dos elementos que estruturam a epistemologia da prática pedagógica docente em sala de aula. Sob essa ótica, as alterações no habitus professoral dos professores temporários na universidade pública podem influenciar 
não só o planejamento de ensino, mas também as aulas ministradas, além de acarretar prejuízos para o desenvolvimento de projetos de pesquisa e extensão na instituição que promove esse tipo de contratação.

Situação possivelmente semelhante a dos professores temporários, verificada nas demais IES públicas estaduais é observada na UEMG, universidade cujo percentual de professores designados é bastante elevado.

Em Minas Gerais existem três IES públicas estaduais, sendo elas a UEMG, a Fundação Helena Antipoff (FHA) e a Universidade Estadual de Montes Claros (UNIMONTES). A UEMG é a maior IES estadual de Minas Gerais. Sobre sua criação, Santos (2015, p. 9-10) afirma que:

\footnotetext{
De acordo com documentos institucionais, a Universidade foi criada pelo Art. 81 do Ato das Disposições Constitucionais Transitórias da Constituição Mineira de 1989. O parágrafo primeiro do Art. 82, do mesmo Ato, proporcionou às fundações educacionais de ensino superior, instituídas pelo Estado ou com sua colaboração, a possibilidade de optarem por ser absorvidas como unidades da UEMG. As fundações incorporadas foram: Fundação Faculdade de Filosofia, Ciências e Letras de Carangola; Fundação Educacional do Vale do Jequitinhonha, em Diamantina; Fundação de Ensino Superior de Passos; Fundação Educacional de Lavras; Fundação de Ensino e Pesquisa do Sul de Minas, em Varginha; Fundação Educacional de Divinópolis; Fundação Educacional de Patos de Minas; Fundação Educacional de Ituiutaba e Fundação Cultural Campanha da Princesa, de Campanha. O movimento de incorporação compreende a absorção de unidades educacionais, no caso, as fundações à Universidade do Estado. Nesse processo, a UEMG assume o controle da instituição, absorve seu patrimônio, bem como, suas dívidas, quando houver.
}

A UEMG, conhecida por ser uma universidade "multicampi", está presente na capital Belo Horizonte e em mais 15 municípios do interior de Minas Gerais. Possui 20.756 alunos matriculados, 1.611 professores, 117 cursos de Graduação, 37 cursos de Pós-Graduação (LAMBERT; ALVES; VIEIRA JÚNIOR, 2017).

Além dos professores efetivos e dos designados, entre os anos de 2007 a 2015, existiu uma terceira classificação de docentes, os efetivados ${ }^{\mathrm{ii}}$, cuja permanência nos cargos foi inicialmente legitimada pela Lei Complementar $n^{\circ}$ 100/2007 (LC 100) (MINAS GERAIS, 2007). No entanto, essa lei foi considerada inconstitucional pelo Supremo Tribunal Federal (STF) através da ADI 4876 (BRASIL, 2014), e, por conseguinte, no dia 31 de dezembro de 2015 , todos os docentes efetivados foram exonerados de seus cargos.

Pode-se considerar que a hierarquia de classificações na UEMG é reduzida, quando comparada a outras IES públicas. Isso porque, desde a exoneração dos efetivados pela LC 100, há somente duas classificações, sendo elas: i) os docentes efetivos, que são os aprovados em concurso público de provas e/ou provas e títulos, como previsto no artigo 37, inciso II, da

\begin{tabular}{l|c|c|c|c|c|c} 
() Rev. Educ. Perspec. & Viçosa, $M G$ & v.9 & n.3 & p.694-713 & set./dez. 2018 & eISSN 2178-8359 \\
\hline
\end{tabular}


Constituição Federal (CF) e que, por isso, contam com estabilidade no emprego; ii) os professores designados, aqueles contratados por meio de um PSS, apenas por um período determinado e que, por isso, não possuem estabilidade no emprego.

Após a exoneração dos efetivados da Lei 100/2007, a hierarquia de classificação entre os docentes da UEMG, passou a se constituir por $92 \%$ de designados e $8 \%$ de efetivos. Tal discrepância começou a diminuir somente no segundo semestre de 2017, quando se iniciaram as nomeações dos professores aprovados no concurso público de 2014.

Sobre as classificações hierárquicas no meio acadêmico, Bourdieu (2007, p. 213) afirma que,

Esta regulação externa que se impõe através da hierarquia das instâncias - o professor universitário cioso de melhorar sua classificação deve respeitar as classificações em vigor, tanto nas suas produções como na sua prática universitária - não faz nada mais do que reforçar os efeitos das disposições automaticamente ajustadas e conformes que foram selecionadas e inculcadas através de todas as operações anteriores de classificação.

Destarte, o desejo do professor designado é tornar-se um dia, efetivo. Isso se deve ao fato de que o professor efetivo possui mais "privilégios" e um plano de carreira que proporcione uma remuneração melhor que a recebida pelo professor designado.

Mancebo (2007b) constata que as contratações temporárias de professores nas universidades públicas têm sido uma prática constante, além de incentivada por muitos de maneira acrítica, devido ao enxugamento orçamentário.

Ao passo que na Universidade do Estado do Rio de Janeiro (UERJ), os professores substitutos são impedidos de realizar diversas atividades acadêmicas, como desenvolver pesquisa e extensão, orientar trabalhos de conclusão de curso e participar das reuniões departamentais (MANCEBO; GOULART; DIAS, 2010), na UEMG, os professores designados gozam de todos esses direitos.

O Decreto n. 46477 (MINAS GERAIS, 2014) de absorção da Fundação Educacional de Divinópolis pela UEMG, que apresenta semelhanças em relação às últimas unidades estadualizadas (Ituiutaba, Campanha, Diamantina, Carangola e Passos), aponta que:

Art. 14. Com a finalidade de assegurar a continuidade das atividades transferidas à UEMG, sem prejuízo da continuidade do semestre letivo, os professores e funcionários administrativos cujos contratos trabalhistas formais serão rescindidos, e que manifestem interesse, poderão ser designados ou contratados pela UEMG (MINAS GERAIS, 2013).

$\mathrm{O}$ artigo acima amparou professores das fundações de ensino superior, que defendiam a recondução automática, absorvidas pela UEMG ao se tornarem designados. O texto do

\begin{tabular}{l|c|c|c|c|c|c|} 
(C) Rev. Educ. Perspec. & Viçosa, $M G$ & v.9 & n.3 & p.694-713 & set./dez. 2018 & eISSN 2178-8359 \\
\hline
\end{tabular}


decreto era usado como defesa para a recondução automática desses professores, ou seja, sucessivas recontratações até que fosse realizado um concurso público de provas e títulos, para oferta de cargos efetivos. Contudo, em janeiro de 2016, os professores designados da UEMG, das unidades recém-absorvidas, sendo elas localizadas nas cidades mineiras de Passos, Divinópolis, Ituiutaba, Campanha, Diamantina e Carangola, foram notificados de que seus contratos de trabalho não seriam renovados.

Naquele ano, diversas mobilizações foram realizadas nas referidas unidades da UEMG para que os contratos dos professores designados da universidade fossem renovados, de modo que houvesse a recondução automática dos cargos ocupados pelos professores até a realização do concurso público, previsto pelo decreto de absorção das unidades à UEMG. Conforme a reportagem da Folha da Manhã (2016), os docentes e discentes das unidades de Passos e de Divinópolis da UEMG temiam que ocorresse um atraso no início do ano letivo em decorrência da inexistência de tempo necessário para a realização do PSS.

Após negociações realizadas, envolvendo a comunidade acadêmica, alguns deputados simpatizantes da causa, o secretário de governo de $\mathrm{MG}$, e representantes dos órgãos da Advocacia Geral do Estado (AGE) e da Secretaria de Planejamento e Gestão (SEPLAG), os professores receberam um parecer favorável à sua recondução automática de 2015 para 2016, mediante publicação no Diário Oficial.

Não obstante, em setembro de 2016, o mesmo dilema voltou a afetar os professores temporários das unidades absorvidas pela UEMG. Uma nova notificação do governo estadual informava que não reconduziria automaticamente o cargo dos professores designados em 2016 para o ano de 2017. Novas negociações e intensas manifestações garantiram a recondução automática, mas somente por mais um ano, visto que em 31 de dezembro de 2017 o processo foi extinto.

Tendo em vista que "o jogo que ocorre em espaços ou "campos" sociais é competitivo, com vários agentes utilizando estratégias diferentes para manter ou melhorar suas posições" (GRENFELL, 2018, p. 98), todos os docentes designados da UEMG passaram a participar de PSS para pleitear vagas e se manterem empregados. Estar atento à divulgação, ao cronograma e aos critérios adotados para a seleção de docentes da UEMG tornou-se condição sine qua non para disputar o jogo desse "campo" social. 


\title{
AS IMPLICAÇÕES DO PSS DA UEMG PARA O TRABALHO DOCENTE
}

Podemos afirmar que a instabilidade dos cargos dos professores designados da UEMG impactou de forma negativa o trabalho docente nos anos de 2016 e 2017 . O cenário instável promoveu intensa preocupação dos docentes designados diante da possibilidade de não obterem outro emprego, terem a interrupção de seus projetos de pesquisa e extensão, bem como com a ausência de motivações para ministrarem suas aulas, proporem novos projetos ou mesmo aderirem a outros. O desabafo de um dos docentes da UEMG, em entrevista à Anna Silva do jornal eletrônico G1 Centro-Oeste de Minas, citado a seguir, reflete a preocupação dos designados no ano de 2016:

\begin{abstract}
Alexandre Simões, coordenador do curso de Psicologia da UEMG, disse que o ponto-chave é que se não houver um posicionamento oficial, que indique a manutenção das designações atuais, para 2017, os projetos de pesquisas e extensão correm riscos de não serem mantidos. "Não se trata somente de termos professores, sejam novos ou os atuais para darem aula. Além das aulas, há projetos, grupos de pesquisa, ações que requerem certa tranquilidade na continuidade das pessoas. Os atuais designados têm contrato até o final de dezembro e o que queremos é que já haja um documento que indique a manutenção destas mesmas pessoas, o que implica na manutenção das ações mais amplas do que dar ou não as aulas. A retórica de que há um cronograma para o concurso, que é também desejado, ofusca este problema das designações, que é muito sério", destacou (SILVA, 2016, online).
\end{abstract}

A realização do PSS para a contratação dos professores designados por um ano, sendo prorrogável pelo mesmo período, revela-se como uma medida rentável para o governo estadual. Isso acontece porque na realidade, os professores que são exonerados em dezembro, quando retornam à universidade, mediante aprovação no PSS, para o ano seguinte, somente terão seus contratos (re)iniciados em meados do mês de fevereiro, ou posteriormente a isso, pois existem casos de professores cuja publicação do seu contrato no Diário Oficial ocorreu apenas no mês de março. Esse atraso nas contratações, que tanto pode ser proposital ou apenas morosidade do processo, rende ao governo estadual uma economia na folha de pagamento dos servidores públicos. Desse modo, percebe-se que o crescimento da força de trabalho docente continua sendo caracterizado pela flexibilização dos contratos trabalhistas, gerando possibilidades de contratação precária (BOSI, 2007).

Na Tabela 1 apresentada a seguir, a remuneração dos professores designados da UEMG é definida conforme a titulação do docente e a carga horária do cargo ocupado, sendo o mesmo de 20 ou 40 horas. 
Tabela1. Remuneração Mensal dos Professores Designados da UEMG*

\begin{tabular}{cccccc}
\hline $\begin{array}{c}\text { Nível } \\
\text { (Titulação) }\end{array}$ & $\begin{array}{c}\text { Regime de } \\
\text { trabalho }\end{array}$ & $\begin{array}{c}\text { Vencimento } \\
\text { básico }\end{array}$ & $\begin{array}{c}\text { Gratificação } \\
\text { Incentivo à } \\
\text { Docência }\end{array}$ & GDPES** & TOTAL \\
\hline $\begin{array}{l}\text { Nível VI } \\
\text { (Doutor) }\end{array}$ & 20 horas & $1.990,67$ & 398,13 & $1.013,22$ & $3.402,02$ \\
& 40 horas & $3.981,33$ & 796,27 & $2.026,45$ & $6.804,05$ \\
Nível IV & 20 horas & $1.382,41$ & 276,48 & 659,12 & $2.318,01$ \\
(Mestre) & 40 horas & $2.764,82$ & 552,96 & $1.318,24$ & $4.636,02$ \\
& & & & & \\
Nível I & 20 horas & 885,65 & 177,13 & 303,71 & $1.366,49$ \\
(especialista) & 40 horas & $1.771,30$ & 354,26 & 607,41 & $2.732,97$ \\
\hline
\end{tabular}

Fonte: Edital 019/2018 - UEMG, Unidade Passos.

(*) A remuneração inicial deverá ser correspondente à titulação apresentada por ocasião da contratação. (**) Gratificação de Desempenho de Professor de Ensino Superior

A tabela publicada em um dos editais de PSS da UEMG do ano de 2018 apresenta a remuneração mensal recebida pelos professores designados que, se comparada com a de outras universidades públicas, apresenta-se inferior. Exemplo de remuneração superior ao do professor designado da UEMG é a do professor substituto da Universidade Estadual do Rio Grande do Sul (UERGS), que, conforme o edital 01/2018 dessa instituição, estabelece a remuneração de 8.257,63 reais para o cargo de professor com título de doutorado para carga horária de 40 horas.

Passos (2014, p. 351), sinaliza "que a forma de remuneração do professor substituto desqualifica o profissional, que recebe bem abaixo do salário do professor efetivo e até mesmo do piso municipal para os professores de IES privadas". Do mesmo modo, a baixa remuneração dos professores designados da UEMG, em relação à remuneração dos professores de outras IES públicas estaduais e federais, representa um elemento de precarização do trabalho docente. A maior parcela de docentes da UEMG ocupam cargos de 20 horas, sendo a remuneração recebida considerada insuficiente para as condições de vida de professores universitários e para o desenvolvimento de atividades de pesquisa e extensão já que esse necessita, dentre outras coisas, viajar para participar de congressos, comprar livros acadêmicos atualizados e investir na formação continuada.

Desse modo, pode-se pressupor que os professores designados da UEMG que ocupam cargos de 20 horas conciliam o seu trabalho na universidade com outros empregos, com o objetivo de complementação salarial. Deste modo, tendo em vista que "o habitus é estruturado pelas condições materiais da existência e também gera práticas, crenças, percepções, sentimentos etc., de acordo com sua própria estrutura" (GRENFELL, 2018, p. 76), a dedicação ao ensino, à pesquisa e à extensão na universidade é afetada pela diminuição de tempo disponível e pela baixa remuneração desses professores. 
A seguir, apresenta-se um exemplo de quadro de vagas ofertado por um dos PSS da UEMG. O quadro apresenta apenas os dois primeiros cargos ofertados por este PSS, cujo total de vagas ofertadas era 227.

Quadro 1. Quadro de vagas do Edital 019/2018 da UEMG, Unidade Passos

\begin{tabular}{|c|c|c|c|c|c|c|c|c|}
\hline \multirow{2}{*}{$\begin{array}{c}\text { Identificação } \\
\text { vaga }\end{array}$} & \multirow[t]{2}{*}{ Curso } & \multirow[t]{2}{*}{ Semestre } & \multirow[t]{2}{*}{ Disciplina } & \multirow[t]{2}{*}{ Turno } & \multirow{2}{*}{$\begin{array}{c}\text { Total } \\
\text { de } \\
\text { vagas }\end{array}$} & \multicolumn{2}{|c|}{$\begin{array}{c}\text { Formação acadêmica } \\
\text { exigida }\end{array}$} & \multirow{2}{*}{$\begin{array}{c}\text { Jornada } \\
\text { semanal } \\
\text { de } \\
\text { trabalho }\end{array}$} \\
\hline & & & & & & Graduação & $\begin{array}{c}\text { Pós- } \\
\text { Graduação }\end{array}$ & \\
\hline \multirow{4}{*}{1} & \multirow{4}{*}{$\begin{array}{c}\text { Educação } \\
\text { Física }\end{array}$} & \multirow{2}{*}{$1^{\circ}$} & $\begin{array}{c}\text { Ginástica } \\
\text { Atividades } \\
\text { Rítmicas e } \\
\text { Expressivas }\end{array}$ & \multirow{4}{*}{$\mathrm{N}$} & \multirow{4}{*}{1} & \multirow{4}{*}{$\begin{array}{l}\text { Educação } \\
\text { Física }\end{array}$} & \multirow{4}{*}{$\begin{array}{l}\text { Ciências da } \\
\text { Saúde }\end{array}$} & \multirow{4}{*}{$20 \mathrm{~h}$} \\
\hline & & & $\begin{array}{l}\text { Ginástica de } \\
\text { Academia }\end{array}$ & & & & & \\
\hline & & \multirow{2}{*}{$2^{\circ}$} & $\begin{array}{l}\text { Atividade } \\
\text { Física e } \\
\text { Promoção } \\
\text { da Saúde }\end{array}$ & & & & & \\
\hline & & & $\begin{array}{c}\text { Ginástica } \\
\text { Laboral }\end{array}$ & & & & & \\
\hline \multirow{5}{*}{2} & \multirow{5}{*}{$\begin{array}{l}\text { Educação } \\
\text { Física }\end{array}$} & \multirow{3}{*}{$1^{\circ}$} & Biomecânica & \multirow{5}{*}{$\mathrm{N}$} & \multirow{5}{*}{1} & \multirow{5}{*}{$\begin{array}{l}\text { Educação } \\
\text { Física }\end{array}$} & \multirow{5}{*}{$\begin{array}{l}\text { Ciências da } \\
\text { Saúde }\end{array}$} & \multirow{5}{*}{$20 \mathrm{~h}$} \\
\hline & & & Musculação & & & & & \\
\hline & & & Atletismo & & & & & \\
\hline & & \multirow[b]{2}{*}{$2^{\circ}$} & Cinesiologia & & & & & \\
\hline & & & $\begin{array}{l}\text { Medidas e } \\
\text { Avaliação } \\
\text { em } \\
\text { Educação }\end{array}$ & & & & & \\
\hline
\end{tabular}

Fonte: Edital 019/2018 da UEMG, Unidade Passos.

Nos editais de PSS da UEMG, todos os cargos ofertados são de 20 horas de trabalho. Nota-se a possibilidade do governo estadual economizar com a contratação dos professores designados, tendo em vista que a remuneração recebida pelos docentes será menor. A aprovação pelo PSS abre a possibilidade de solicitação de ampliação de carga horária para 40 horas, desde que devidamente justificada. Os professores que ocupam os cargos de 40 horas são geralmente aqueles que desenvolvem projetos de pesquisa e/ou extensão com alunos bolsistas e que tenham tido aprovação em edital para ampliação de carga horária; chefes de departamentos; direção e vice-direção acadêmica, coordenadores de pesquisa, extensão e de Laboratórios.

Há cargos que são muito disputados, atraindo candidatos de municípios distantes. Por outro lado, há vagas que não são preenchidas, devido à inexistência de candidatos interessados, a exemplo de cargos de professores para o curso de Medicina, visto que a remuneração dos docentes é tida como inferior para um graduado nessa área. 
Conforme afirma Bourdieu (2017, p. 70):

O campo universitário reproduz na sua estrutura o campo do poder cuja ação própria de seleção e de inculcação contribui para reproduzir a estrutura. É na verdade no e por seu funcionamento como espaço de diferenças entre posições (e, da mesma maneira, entre as disposições de seus ocupantes) que se realiza, fora de toda intervenção das consciências e das vontades individuais ou coletivas, a reprodução do espaço das posições diferentes que são constitutivas do campo do poder.

As disputas no "campo" são evidenciadas no momento da participação dos candidatos às vagas no PSS. Cada candidato pode, de acordo com o edital de 2018 da UEMG, pleitear três vagas, podendo assumir, em caso de aprovação, até duas. No entanto, para assumir duas vagas, os horários de aula precisam ser conciliáveis.

O "campo" "é um espaço de lutas, uma arena onde está em jogo uma concorrência ou competição entre os agentes que ocupam as diversas posições" (LAHIRE, 2017, p. 65). Por esse motivo, os professores (agentes), às vezes, precisam concorrer a vagas que antes eram ocupadas por amigos, ocasionando constrangimentos entre eles.

No quadro 2 é apresentado o quadro de pontuação para a avaliação do currículo Lattes dos candidatos, conforme o PSS da UEMG. O quadro foi extraído de um dos editais de PSS, mas também se aplica aos demais. Toda a documentação dos candidatos deve ser devidamente comprovada e enviada à Comissão de Designação Temporária da UEMG que, por meio de professores avaliadores da mesma instituição, avaliam os currículos e promovem a somatória dos pontos para a classificação. 
Quadro 2. Quadro de Pontuação pelo PSS da UEMG

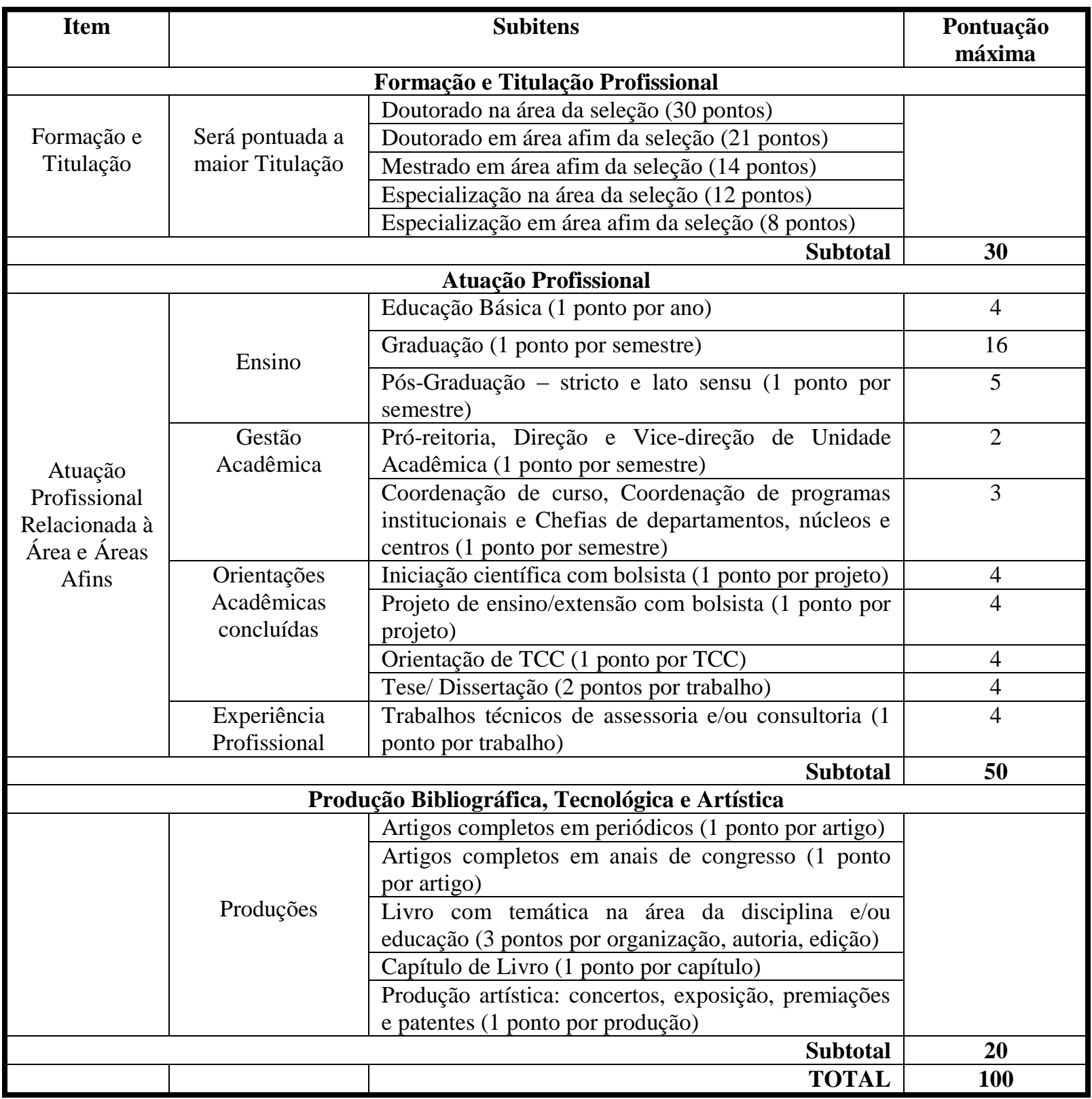

Fonte: Edital 019/2018 da UEMG, Unidade Passos.

Por meio da observação do que é pontuado para a aprovação no PSS, nota-se uma diversidade de quesitos, que abrangem não somente a titulação, a atuação profissional e a produção bibliográfica, como também a produção tecnológica e artística dos candidatos a professores designados da UEMG. Ademais, "apenas os que tiverem incorporado o habitus próprio do "campo" estão em condições de disputar o jogo e de acreditar na importância dele" (LAHIRE, 2017, p. 65). Assim, constata-se que mesmo com instabilidade no emprego e com uma remuneração baixa, o professor designado da UEMG precisa aderir ao produtivismo 
acadêmico, cujo objetivo será elevar a pontuação para posterior aprovação no PSS, visto que disputará uma vaga novamente, em períodos de tempo relativamente curtos.

Entende-se, assim como Lahire (2017, p. 65) que "cada "campo" possui regras do jogo e desafios específicos, irredutíveis às regras do jogo e aos desafios dos outros "campos". Em virtude disso, os professores incorporam essas regras, que são os quesitos pontuados pelo PSS. Com o quadro de pontuação para o PSS em mente, os professores designados buscam produzir academicamente somente o que poderá ser pontuado. Deste modo, apresentar trabalhos em congressos, realizar palestras e minicursos, participar de bancas de trabalhos de conclusão de cursos, escrever artigos para jornais, entre outros, deixam de ser prioridade para os docentes, visto que tais atividades não os farão aumentar a pontuação no PSS seguinte. Por outro lado, na ânsia de ampliar a somatória de pontos, grupos de professores se unem para ampliar sua produção acadêmica por meio de publicações coletivas.

O terceiro quadro apresenta uma das vagas ofertadas pelo PSS da UEMG da qual pretende-se ressaltar a diversidade de conteúdos disciplinares.

Quadro 3. Vaga 40 do Edital 019/2018 da UEMG

\begin{tabular}{|c|c|c|c|c|c|c|c|c|}
\hline \multirow{2}{*}{$\begin{array}{c}\text { Identificação } \\
\text { vaga }\end{array}$} & \multirow[t]{2}{*}{ Curso } & \multirow[t]{2}{*}{ Semestre } & \multirow[t]{2}{*}{ Disciplina } & \multirow[t]{2}{*}{ Turno } & \multirow{2}{*}{$\begin{array}{c}\text { Total } \\
\text { de } \\
\text { vagas }\end{array}$} & \multicolumn{2}{|c|}{$\begin{array}{c}\text { Formação acadêmica } \\
\text { exigida }\end{array}$} & \multirow{2}{*}{$\begin{array}{c}\text { Jornada } \\
\text { semanal } \\
\text { de } \\
\text { trabalho }\end{array}$} \\
\hline & & & & & & Graduação & $\begin{array}{c}\text { Pós- } \\
\text { Graduação }\end{array}$ & \\
\hline \multirow{9}{*}{40} & História & & $\begin{array}{c}\text { Iniciação } \\
\text { aos Estudos } \\
\text { Históricos }\end{array}$ & \multirow{9}{*}{$\mathrm{N}$} & \multirow{9}{*}{1} & \multirow{9}{*}{ História } & \multirow{9}{*}{$\begin{array}{l}\text { História ou } \\
\text { Educação }\end{array}$} & \multirow{9}{*}{$20 \mathrm{~h}$} \\
\hline & Pedagogia & $1^{\circ}$ & $\begin{array}{l}\text { Geografia } \\
\text { Humana }\end{array}$ & & & & & \\
\hline & $\begin{array}{l}\text { Ciências } \\
\text { Contábeis }\end{array}$ & & $\begin{array}{l}\text { Metodologia } \\
\text { de Pesquisa }\end{array}$ & & & & & \\
\hline & & & $\begin{array}{l}\text { Pesquisa } \\
\text { Educacional }\end{array}$ & & & & & \\
\hline & & & $\begin{array}{l}\text { Trabalho de } \\
\text { Conclusão } \\
\text { de Curso I }\end{array}$ & & & & & \\
\hline & História & \multirow{4}{*}{$2^{\circ}$} & $\begin{array}{l}\text { Geografia } \\
\text { Física }\end{array}$ & & & & & \\
\hline & Pedagogia & & $\begin{array}{c}\text { Trabalho de } \\
\text { Conclusão de } \\
\text { Curso }\end{array}$ & & & & & \\
\hline & $\begin{array}{l}\text { Ciências } \\
\text { Contábeis }\end{array}$ & & \begin{tabular}{|c} 
Prática \\
Formativa \\
VIII - TCC
\end{tabular} & & & & & \\
\hline & & & $\begin{array}{c}\text { Trabalho de } \\
\text { Conclusão de } \\
\text { Curso II }\end{array}$ & & & & & \\
\hline
\end{tabular}

Fonte: Edital 019/2018 da UEMG, Unidade Passos.

(C) Rev. Educ. Perspec.

Viçosa, $M G$

v.9

n.3

p.694-713

set./dez. 2018

eISSN 2178-8359 
A vaga de número 40 do edital 019/2018 da UEMG, Unidade de Passos apresenta um bom exemplo do acúmulo de disciplinas e da diversidade de cursos a que um professor designado poderá estar sujeito, se aprovado. Essa forma de agrupamento de disciplinas deve-se, principalmente, ao fato da unidade não estar dividida em departamentos. Desse modo, o professor designado para esta vaga terá que lecionar cinco disciplinas em três cursos distintos no primeiro semestre e quatro disciplinas em três cursos no segundo semestre. Constata-se, assim, que o mesmo professor precisa dominar conteúdos da área de História, Geografia, Educação e Metodologia Científica, sendo que possivelmente uma ou mais disciplinas não terão aderência com a sua formação acadêmica. $O$ acúmulo de disciplinas e cursos verificados nesta vaga tem ocorrido em outras vagas também, o que revela uma intensificação do trabalho docente.

Ainda em relação à vaga 40, o mesmo professor terá que participar de reuniões de colegiado de três cursos diferentes por semestre; elaborar cinco planos de ensino, e cinco avaliações de conteúdos distintos; preparar aulas de cinco disciplinas diferentes e preencher cinco diários. Tudo isso somente no primeiro semestre. Terá ainda um número elevado de alunos por semestre. Destarte, verifica-se que o habitus professoral dos docentes diante das lutas no "campo" científico passa por alterações significativas (BOURDIEU, 1983), visto que os professores designados da UEMG precisam adaptar-se às condições impostas pelo cargo que ocupam e preparar-se para a obtenção de novas vagas no PSS dos anos posteriores.

\section{CONSIDERAÇÕES FINAIS}

As medidas neoliberais de flexibilização das relações de trabalho têm se manifestado na UEMG por meio da manutenção do elevado número de professores designados. As condições precárias de trabalho destes professores, apesar de suas particularidades, apresentam-se também semelhantes às condições de trabalho dos professores temporários de outras universidades públicas estaduais.

Por meio da análise dos dados presentes no PSS 019/2018 da UEMG, Unidade Passos, constatou-se que as condições de trabalho dos professores designados da UEMG têm se caracterizado pela precarização. Os professores temporários lecionam muitas disciplinas por semestre, além das mesmas nem sempre possuírem aderência à sua formação acadêmica; recebem baixa remuneração em relação à remuneração de professores que lecionam em outras IES públicas estaduais e federais e têm projetos de pesquisa e extensão interrompidos pelo vencimento dos contratos trabalhistas.

O elevado índice de professores que ocupam cargos de 20 horas também revela condições precárias de trabalho, pois precisam buscar trabalho em outras instituições para

\begin{tabular}{l|c|c|c|c|c|c|}
\hline (C) Rev. Educ. Perspec. & Viçosa, $M G$ & v.9 & n.3 & p.694-713 & set./dez. 2018 & eISSN 2178-8359 \\
\hline
\end{tabular}


complementação da renda e, possivelmente, apresentam dificuldades de conciliação de horários e de cumprimento das atribuições do cargo ocupado na UEMG.

O fato de precisarem se submeter ao PSS anualmente ou a cada dois anos faz com que muitas tensões, bem como disputas no "campo", sejam vivenciadas entre os docentes que, mesmo com precárias condições de trabalho precisam entrar na lógica do produtivismo acadêmico visando maior pontuação no PSS do qual participarão futuramente. Deste modo, o seu habitus professoral passa por alterações, visto que priorizam apenas o que é pontuado pelo PSS em detrimento da preparação de aulas com boa qualidade, por exemplo.

Por outro lado, a possibilidade de não obtenção de um novo cargo para professor temporário por meio do PSS faz com que os professores designados desenvolvam apenas atividades de curta duração. Exemplo disso são os projetos que deveriam ser desenvolvidos em dois anos, mas passam a ser desenvolvidos somente em um, devido à possibilidade de o professor orientador não estar vinculado à UEMG no ano seguinte. Nota-se, com essas práticas, uma alteração no habitus professoral dos docentes designados.

O PSS, que deveria ocorrer apenas temporariamente em situações de substituição de docentes com afastamento da função, lamentavelmente tem se tornado uma prática duradoura. $\mathrm{O}$ concurso público de provas e títulos, como previsto pela Constituição Federal, para efetivação dos docentes das extintas fundações absorvidas pela UEMG, inúmeras vezes prometido por agentes públicos, até o momento da produção deste artigo não se concretizou.

No atual cenário político, marcado por aprovações de políticas neoliberais como o teto de gastos públicos estipulado para 20 anos, pela terceirização e pela reforma trabalhista, entende-se que as ações em defesa da realização de um concurso público tem se enfraquecido. Torna-se urgente que mobilizações sejam realizadas por servidores e estudantes da UEMG para que a luta pela realização do concurso público para os docentes permaneça. De resto, com a continuidade do PSS, o que se constatará é a permanência das condições precárias de trabalho dos professores designados.

\section{REFERÊNCIAS}

AMADO, Luis Antonio Saléh; MANCEBO, Deise. A universidade no século XXI: entre o discurso e a prática. Série-Estudos. Campo Grande - MS, n. 16, p. 93-106, jul./dez., 2003. Disponível em: http://www.serie-estudos.ucdb.br/index.php/serieestudos/article/view/510/404. Acesso em: 03 mar. 2018.

ANTUNES, Ricardo. Os sentidos do trabalho: ensaio sobre a afirmação e a negação do trabalho. 2 ed. São Paulo: Boitempo, 2009.

\begin{tabular}{l|l|l|l|l|l|l} 
(C) Rev. Educ. Perspec. & Viçosa, $M G$ & v.9 & n.3 & p.694-713 & set./dez. 2018 & eISSN 2178-8359 \\
\hline
\end{tabular}


BALDINO, José Maria; DONENCIO, Maria Conceição Barbosa. O habitus professoral na constituição das práticas pedagógicas. Polyphonía, v. 25, n. 1, jan./jun. 2014. Disponível em: https://www.revistas.ufg.br/sv/article/viewFile/38563/19509. Acesso em: 03 mar. 2018.

BOSI, Antônio de Paula. A precarização do trabalho docente nas instituições de ensino superior do Brasil nesses últimos 25 anos. Educação e Sociedade, Campinas, v. 28, n. 101, p. 1503-1523, set./dez. 2007. Disponível em: http://www.scielo.br/pdf/es/v28n101/a1228101.pdf. Acesso em: 31 mar. 2018.

BOURDIEU, Pierre. O campo científico. In: ORTIZ, Renato (Org.). Pierre Bourdieu: sociologia. Trad. Paula Monteiro e Alícia Auzmendi. São Paulo: Ática, 1983. P. 122-155.

BOURDIEU, Pierre. A distinção: crítica social do julgamento. Trad. Daniela Kern; Guilherme João de Freitas Teixeira. São Paulo: Edusp, 2007.

BOURDIEU, Pierre. Homo Academicus. Trad. Ione Ribeiro Valle, Nilton Valle. 2 ed. Florianópolis: Editora da UFSC, 2017.

BRASIL. Supremo Tribunal Federal. ADI n 4.876, Inteiro Teor do Acórdão. Relator: Ministro Dias Toffoli. Brasília, DF, 26 de março de 2014. Disponível em: http://redir.stf.jus.br/paginadorpub/paginador.jsp?docTP=TP\&docID=6272695. Acesso em: 03 jun. 2018.

CHAUÍ, Marilena. A universidade operacional. Folha de São Paulo. Caderno Mais! 9 de maio de 1999. Disponível em: http://reuniufpr.forumeiros.com/t46-a-universidadeoperacional-marilena-chaui. Acesso em: 05 ago. 2018.

CHESNAIS, François. A mundialização do capital. Trad. Silvana Finzi Foá. São Paulo: Xamã, 1996.

FOLHA DA MANHÃ. Professores da UEMG ficam sem seus cargos e temem o “apagão". 12 de jan. de 2016. Disponível em: http://www.clicfolha.com.br/imprimirmateria/53626/professores-da-uemg-ficam-sem-seus-cargos-e-temem-o-apagao. Acesso em: 03 jun. 2018.

GIL, Antonio Carlos. Métodos e Técnicas de Pesquisa Social. 6 ed. São Paulo: Atlas, 2008.

GRENFELL, Michael. Pierre Bourdieu: conceitos fundamentais. Trad. Fábio Ribeiro. Petrópolis, RJ: Vozes, 2018.

HARVEY, David. O neoliberalismo: história e implicações. Trad. Adail Sobral; Maria Stela Gonçalves, 5 ed. São Paulo: Edições Loyola, 2014. 
JORNAL DA UEMG. Conhecimento Vital. Universidade do Estado de Minas Gerais, maio 2016. Disponível em: http://intranet.uemg.br/comunicacao/jornal/05_16/. Acesso em: 02 jun. 2018.

LAMBERT, Márcio Moreira; ALVES, Roberto Werneck Resende; VIEIRA JÚNIOR, Waldyr Dias (Org.). UEMG: unidade na Diversidade. Belo Horizonte: EdUEMG, 2017.

LAHIRE, Bernard. Campo. In: CATANI, Afrânio Mendes et al. (Org.). Vocabulário Bourdieu. Belo Horizonte: Autêntica Editora, 2017. P. 64-66.

MANCEBO, Deise. Agenda de pesquisa e opções teórico-metodológicas nas investigações sobre trabalho docente. Educação e Sociedade, Campinas, v. 28, n. 99, p. 466-482, maio/ago. 2007a. Disponível em: http://www.scielo.br/pdf/es/v28n99/a09v2899.pdf. Acesso em: 01 jun. 2018.

MANCEBO, Deise. Trabalho docente: subjetividade, sobreimplicação e prazer. Psicologia: Reflexão e Crítica. Porto Alegre, v. 20, n. 1, p. 74-80, 2007 b.

MANCEBO, Deise; GOULART, Samira Meletti da Silva; DIAS, Viviane da Cunha. Trabalho Docente na UERJ (1995-2008): intensificação, precarização e efeitos de subjetivação. SEMINÁRIO INTERNACIONAL DA REDE DE PESQUISADORES SOBRE ASSOCIATIVISMO E SINDICALISMO DOS TRABALHADORES EM EDUCAÇÃO. Rio de Janeiro, abr. 2010. Anais... Rio de Janeiro, abr. 2010. Disponível em:

http://www.rephip.unr.edu.ar/bitstream/handle/2133/3987/Mancebo,\%20Goulart\%20e\%20Di as.pdf?sequence $=3$. Acesso em: 30 maio 2018.

MINAS GERAIS. Lei Complementar 100, de 05 de novembro de 2007. Institui a unidade de gestão previdenciária integrada - ugeprevi - do regime próprio de previdência dos servidores públicos do estado de minas gerais e do regime próprio de previdência dos militares do estado de minas gerais e o conselho estadual de previdência - ceprev -, altera a lei complementar $n^{\circ} 64$, de 25 de março de 2002, e dá outras providências. 2007. Disponível em: http://www.almg.gov.br/consulte/legislacao/completa/completa.html?tipo=LCP\&num= 100\&ano=2007. Acesso em: 14 fev. 2018.

MINAS GERAIS. Decreto n⿳ 46477, de 03 de abr. de 2014. Regulamenta a absorção, pela Universidade do Estado de Minas Gerais, das atividades de ensino, pesquisa e extensão mantidas pela Fundação Educacional de Divinópolis. MG, abr. 2014.

PASSOS, Rachel Gouveia. O trabalho do professor substituto na FSS/UERJ: limites e impasses frente à precarização. In: VELOSO, Renato dos Santos et al. (Org.) Trajetória da Faculdade de Serviço Social da UERJ: 70 anos de história. Rio de Janeiro: EdUERJ, 2014. p. 339-355.

PIMENTA, Selma Garrido; ANASTASIOU, Léa das Graças Camargos. Docência no Ensino Superior. 5 ed. São Paulo: Cortez, 2014. 
SANTOS, Neide Elisa Portes dos. As transformações no Trabalho docente da Universidade do Estado de Minas Gerais frente às reformas de Estado e da Educação dos anos 2000. REUNIÃO NACIONAL DA ANPED, 37, Florianópolis, UFSC, out. 2015. Anais... Florianópolis, UFSC, out. 2015. Disponível em: http://37reuniao.anped.org.br/wpcontent/uploads/2015/02/Trabalho-GT11-4233.pdf. Acesso em: 03 jun. 2018.

SANTOS, Neide Elisa Portes dos. Gestão e Trabalho na Universidade: as recentes reformas do Estado e da Educação Superior e seus efeitos no trabalho docente na UEMG. 2014. 269 f. Tese (Doutorado em Educação). Universidade Federal de Minas Gerais, Faculdade de Educação da UFMG, Belo Horizonte, 2014.

SANTOS, Neide Elisa Portes dos; VIEIRA, Lívia Fraga. A (re) configuração do trabalho docente na Universidade do Estado de Minas Gerais frente às reformas de Estado e da Educação dos anos 2000. Currículo sem Fronteiras, Rio de Janeiro, v. 15, n. 2, p. 409-424, maio/ago. 2015. Disponível em: http://www.curriculosemfronteiras.org/vol15iss2articles/ santos-vieira.pdf . Acesso em: 01 mar. 2018.

SILVA, Anna Lúcia. Professores da UEMG em Divinópolis apoiam protesto e cobram concurso. G1. CENTRO-OESTE-MG. 12 out. 2016. Disponível em:

http://g1.globo.com/mg/centro-oeste/noticia/2016/10/professores-da-uemg-em-divinopolisapoiam-protesto-e-cobram-concurso.html. Acesso em: 01 mar. 2018.

TAVARES, André Luis dos Santos. A precarização do trabalho docente na educação superior: um estudo sobre a contratação temporária de docentes na universidade do estado do Pará. 2011, 267 f. Dissertação (Mestrado em Educação) - Universidade Federal do Pará, Instituto de Ciências da Educação, Belém - PA, 2011.

TRIVIÑOS, Augusto Nibaldo Silva. Introdução à Pesquisa em Ciências Sociais. A pesquisa qualitativa em Educação. São Paulo: Atlas, 1987.

UEMG. Edital n 019/2018. Processo Seletivo Simplificado para designação temporária de professores de educação superior em unidades acadêmicas da Universidade do Estado de Minas Gerais - UEMG- ano de 2018. Disponível em: http://intranet.uemg.br/designacao/ arquivos/Arq20180111155148.pdf. Acesso em: 03 jun. 2018.

WACQUANT, Loïc. Habitus. In.: CATANI, Afrânio Mendes et al. (Org.). Vocabulário Bourdieu. Belo Horizonte: Autêntica Editora, 2017. P. 213-217.

\section{NOTAS}

\footnotetext{
${ }^{\text {i }}$ Nome atribuído em Minas Gerais aos professores temporários.

ii $\mathrm{O}$ professor efetivado ocupava uma espécie de cargo híbrido de efetivo e designado, pois não havia sido aprovado em concurso público, mas possuía uma relativa estabilidade no cargo. A efetivação de aproximadamente 98 mil servidores públicos do estado de MG no dia 05 de novembro de 2007 foi resultado de uma tentativa do governo estadual resolver questões trabalhistas e previdenciárias (SANTOS; VIEIRA, 2015).
}

(C) Rev. Educ. Perspec.

Viçosa, $M G$

v.9

n. 3

p.694-713

set./dez. 2018

eISSN 2178-8359 


\section{Sobre os Autores}

1 Adelino Francklin - Doutorando em Educação pela Universidade Federal de São Carlos. Coordenador e Professor do curso de Licenciatura em História da Universidade Estadual de Minas Gerais. Brasil. E-mail: cafrancklin@uol.com.br - ORCID: https://orcid.org/0000-0003-0971-6374

${ }^{2}$ Maria Cristina da Silveira Galan Fernandes - Doutora em Educação Escolar pela Universidade Estadual Paulista "Júlio Mesquita Filho". Professora da Universidade Federal de São Carlos. Brasil. E-mail: mcsgfernandes@gmail.com - ORCID: https://orcid.org/0000-0002-8415-9400 